\title{
제15차 유엔기후변화총회 결과
}

\author{
임 소 영 KOICA 기후변화대응반 연구관
}

유엔기후변화협약의 이행상황을 점검하고 포스트 교토체제의 방향에 관해 합의를 도출하기 위한 유엔기후변화총회가 2009년 12.7 18일 덴마크 코펜하겐 벨라센터에서 개최되었다.

\section{I. 배경 및 개요}

1992년 전 지구적인 온실가스의 배출을 제한하여 온실가스의 대기 중 농도를 감축하기 위해 유엔 기후변화협약 (UNFCCC)이 채택되었다. 이후 1994년 협약이 발효되고 나서부터 매년 개최되는 당 사국회의 (Conference of Parties, $\mathrm{COP}$ )를 통해 회원국들의 협약의 이행상황을 점검하고 전 지구 적인 기후변화 관련 당면과제를 해결하기 위한 논의 및 결정이 이루어져 왔다. 국가별 온실가스 감 축을 최초로 의무화한 교토의정서도 1997년 제3차 당사국회의에서 채택되어 2005년에 발효되었 다.

특히 지난 12 월에 개최된 제 15 차 기후변화협약 당사국회의에서는 2012년에 그 효력이 다하는 교 토의정서를 대체할 새로운 체제의 생성을 목적으로 하여 전 세계의 관심이 집중되었다. 덴마크 코 펜하겐에서 2009년 12.7 18일 동안 열린 유엔기후변화총회는 $\mathrm{COP}^{1)} 15, \mathrm{CMP}^{2)} 5, \mathrm{SBI}^{3)} 31$, $\mathrm{SBSTA}^{4)} 31, \mathrm{AWG}-\mathrm{LCA}^{5)}$ 8, $\mathrm{AWG}-\mathrm{KP}^{6)} 10$ 의 6 개의 회의로 구성되어 진행되었으며, 이들 중 개 발협력과 관련한 재정 지원 및 기술의 이전은 SBI31, SBSTA31, AWG-LCA8에서 주로 다루어졌 다. 제 15 차 코펜하겐 기후변화협약 당사국회의는 법적 효력이 있는 새로운 온실가스 감축의무 체제 를 마련한다는 소기의 목적을 달성하지는 못했지만, 전체회의 결정문에 첨부되는 수준에서 합의가

1) Conference of the Parties (기후변화협약 당사국총회)

2) Conference of the Parties serving as the meeting of the Parties to the Kyoto Protocol (교토의정서 당사국회의)

3) Subsidiary Body for Implementation (이행부속기구회의)

4) Subsidiary Body for Scientific and Technological Advice (과학기술자문부속기구회의)

5) Ad Hoc Working Group on Long-term Cooperative Action under the Convention (장기협력행동 특별작업반회의)

6) Ad Hoc Working Group on Further Commitments for Annex I Parties under the Kyoto Protocol (교토의정서 부속서I 당 사국 추가공약 특별작업반회의) 
이루어진 코펜하겐 합의문 (Copenhagen Accord)을 도출함으로써 포스트 교토체제의 생성을 위한 전 단계를 마련했다는 평가를 받고 있다.

\section{II. 회의 내용}

\section{1. 제 31 차 이행부속기구회의 (SBI $31,12.8-12$ )}

\section{가. 개요}

기후변화협약의 이행과 관련된 모든 문제에 관한 논의와 분석을 하고 적절한 정책적 자문을 제시하 는 전문가 그룹으로서, 주로 국가보고서 (National Communications) 내용 및 당사국에 의해 제출 된 온실가스 인벤토리를 점검하는 업무를 담당하는 SBI는 금번 제31차 회의에서는 국가보고서와 온실가스 인벤토리 자료, 협약의 재정 메커니즘과 기술개발 및 이전 등에 관한 논의를 진행하였다. 특히 협약의 재정 메커니즘은 SBI 의제 5 에서, 기술개발 및 이전은 SBI 의제 7 에서 다루어져 논의 되었다.

\section{나. 핵심내용}

$\mathrm{SBI}$ 의제 5는 i) 재정메커니즘의 제4차 검토, ii) $\mathrm{GEF}$ 보고 및 $\mathrm{GEF}$ 에 대한 지침, iii) 특별기후변화 기금 평가의 하위주제로 구성되어 진행되었다. 금번 회의는 협상 프로세스에 집중하기 위해 부속기 구 회의를 최소화하는 분위기 속에서 특별히 주목할 만한 결정사항은 없었고, $\mathrm{GEF}$ 에 의해 운영되 는 재정메커니즘에 대해 선진국과 개도국 간의 큰 의견 차를 확인하였다.

\section{다. 토의내용}

제 14 차 당사국총회 결정문 4 (decision 4/CP.14)에 따라 권고된 $\mathrm{GEF}$ 운용자금에 대한 당사국의 의견 제출, $\mathrm{GEF}$ 재원의 할당 및 접근, $\mathrm{GEF}$ 사업 처리 절차 간소화 및 효율성 제고 등에 대한 정보 의 제공 등이 주로 논의되었다. $\mathrm{EU}$, 미국 등의 선진국들은 그간 $\mathrm{GEF}$ 의 성과를 높이 평가하면서, $\mathrm{GEF}$ 체제의 유지 및 권한 확대를 원하였다. 반면에 G77\&중국, AOSIS, 아프리카 등 개도국들은 현행 재정 메커니즘인 $\mathrm{GEF}$ 의 제도개선이 필요함을 표명하면서, $\mathrm{GEF}$ 가 제도개선 계획 및 지원거절 사례 등에 대한 정보를 제공할 것을 요구하였다. 금번 회의에서는 협약상의 재정 메커니즘에 대한 논의의 일부 진전을 얻을 수 있었으나, 실질적인 결론을 얻지 못하고 추가적인 협의를 제 32 차 SBI 에서 지속적으로 논의하기로 결정하였다. 


\section{2. 제31차 과학기술자문부속기구회의 (SBSTA 31, 12.8-12)}

가. 개요

$\mathrm{SBSTA}$ 는 주로 과학, 기술, 방법론적인 측면에서 이루어진 사안에 대해 논의하고 과학적 이론을 제 공하는 전문가 그룹으로서, 환경친화적인 기술의 개발 및 이전의 증진과 국가보고서 및 온실가스 인벤토리의 준비를 위한 지침서 개선을 주로 담당하고 있다. 금번 31차 회의에서는 기후변화의 영 향, 취약성 및 적응에 관한 나이로비 작업계획 (SBSTA 의제 3)과 기술의 개발 및 이전 (SBSTA 의 제 4), 개도국의 산림전용으로 인한 배출감축 (REDD) (SBSTA 의제 5) 등의 이슈에 대해 논의하였 다.

\section{나. 핵심내용}

금번 제31차 SBSTA에서는 개도국의 산림전용으로 인한 온실가스 감축과 관련된 의제만 실질적인 합의에 도달하고, 나머지 의제들은 제32차 SBSTA에서 논의하기로 결정되었다.

\section{다. 토의내용}

\section{1) 나이로비 작업계획 결정문 채택}

제30차 SBSTA에서 제안된 결정문 초안이 금번 제31차 SBSTA에서 채택되었다. 결정문에는 지역 에서 국가 단위까지 적응계획과 행동이 확대되고 통합되었으며, 기후변화에 대한 경제적 복원력이 증진되고 경제 다변화를 통해 기후변화에 취약한 경제 분야의 의존이 축소되는 등 나이로비 작업계 획의 이행을 통해 발생한 결과가 정리되었다. 또한 나이로비 작업계획의 실행을 위한 광범위한 조 직들의 기여 및 동참 강화가 촉구되었다.

\section{2) 산림전용으로 의한 온실가스 배출의 저감 (REDD) 결정문 채택}

2007년 제13차 당사국총회에서 생성된 결정문은 REDD에 '산림보전 및 지속적인 산림경영활동을 통한 산림 탄소축적 증진활동’을 포함함으로써 'REDD-plus'로 확대시켰다. REDD-plus에 관한 정치적 접근 및 인센티브 논의는 $\mathrm{AWG}-\mathrm{LCA}$ 에서, 방법론적 이슈는 SBSTA에서 다루었으며, 관련 된 결정문을 채택함으로써 산림의 온실가스 흡수 능력의 중요성을 인정하게 되었다. 


\section{3. 제8차 장기협력행동 특별작업반회의 (AWG-LCA 8, 12.7-15)}

가. 개요

2007년 제13차 당사국총회에서 채택된 발리행동계획에 의해, 부속서I에 속하는 선진국 뿐 아니라 개도국을 포함한 모든 당사국의 중장기적인 온실가스 감축 계획에 대한 논의를 진행하는 특별작업반 회의인 AWG-LCA가 설치되었다. 2008년 3월에 개최된 제1차 회의 이후 장기협력행동을 위한 공유 비전, 감축, 적응, 기술개발과 이전, 재원제공과 투자의 핵심 쟁점 사항에 대해 논의를 실시해 왔다.

\section{나. 핵심내용}

금번 제8차 작업반 회의에서는 제 1 차 회의 이후 축적되어 온 그 동안의 작업반 성과물을 담은 결정 문 초안을 제시하였다. 그 외에 금번 회의는 향상된 적응 활동, 재원과 투자의 제공, 기술개발 및 이 전, 역량배양, 개발도상국의 적절한 감축행동 작성을 위한 지원, $\mathrm{REDD}$ 와 관련된 이슈의 정책적 접 근 및 인센티브 논의, 기후변화 대응 조치에 의한 경제적 · 사회적 파급효과, 감축활동 증진 및 이의 비용효과성 향상을 위한 시장메커니즘 활용을 포함한 다양한 접근법, 농업부문의 분야별 활동 등에 대한 회의문의 결정을 고려하도록 기후변화협약 당사국총회에 결정사항을 제시하였다.

\section{다. 토의내용}

$\mathrm{AWG}-\mathrm{LCA}$ 가 도출한 결정사항들 중 재원 및 투자에 관한 회의에서는 펀드설립과 운영주체 (operating entity) 및 펀드 신탁관리자 (trustee)의 선정 절차 부분이 집중적으로 논의되었다.

\section{1) 펀드 및 운영주체}

미국은 단순한 기금을 초월하여 재원과 그 재원을 운영하는 위원회를 모두 포함하는 넓은 의미의 기후기금 (Climate Facility)을 제안하였다. 그러나 EU는 기존의 GEF와 동일한 성격인 또 다른 재 원 집중 기금 설립에 대해 반대 입장을 표명하면서, 새로운 펀드를 설립하는 것보다 현재의 GEF를 보완하는 방안을 지지하였다. 한편, G77/중국을 중심으로 하는 개도국들은 기존 $\mathrm{GEF}$ 재원에 대해 개도국의 접근성이 매우 부족했음을 지적하면서, 재원의 전달 및 전달 채널이 중요함을 강조하였 다. 협상 결과, 기후기금 (Climate Facility or Fund)이 협약 하 재정 메커니즘의 운영주체로 설립 되는 것으로 결정되었다.

\section{2) 펀드 신탁관리자}

선진국들은 새로 설립되는 펀드의 신탁관리자로서 GEF나 적응기금을 관리집행하고 있는 세계은행 
이 적합하다는 입장인 반면, 개도국들은 지난 15 년간의 경험에서 발견된 $\mathrm{GEF}$ 운영절차의 문제점 을 지적하면서 새로 설립되는 펀드의 신탁관리자는 공개입찰을 통해 공정하게 선정되어야 한다고 주장하였다. 결과적으로 새로운 재정 메커니즘의 재정 위원회는 당사국총회의 지도 하에 설립될 것 이다.

\section{III . 총회 결과 - 코펜하겐 합의문 (Copenhagen Accord)}

미국, 중국, 인도, 브라질, 남아공 5 개국 회의에서 협의안이 마련된 코펜하겐 합의문은 총회에서 유 의 (take note)하기로 결정됨으로써 법적인 구속력은 없지만 유엔 차원의 공식문서로 남게 되었다.

\section{1. 주요 내용}

지구 온도의 상승폭을 산업혁명 이전 대비 $2^{\circ} \mathrm{C}$ 이하로 억제하는 내용에 합의했으며, 그 이행에 관 한 평가를 2015 년까지 완료하기로 하였다. 또한 2015 년에 온도 상승폭을 $1.5^{\circ} \mathrm{C}$ 로 재조정하는 문 제도 검토하기로 하였다.

온실가스 감축목표에 대해서는 비록 구속력은 없지만, 부속서 I 당사국들은 2010년 1월 31일까지 사무국에 2020년까지의 감축목표를 제출하고, 비부속서 I 국가들은 온실가스 감축을 위해 실행할 감축행동을 담은 감축계획보고서를 제출하고 2 년마다 국가보고서를 통해 통보한다는 내용에 합의 하였다.

개발도상국의 기후변화 대응을 위한 재정지원을 위해 최빈국, 군소도서국, 아프리카 등을 우선 지 원하고, 특히 개도국의 삼림보호를 위해서는 35 억 불을 지원하기로 하였다. 구체적인 재정지원 내 용은 2010-2012년까지 새롭고 추가적인 (new and additional) 300억 불을 긴급히 지원하고, 2020년까지 장기적으로는 매년 1,000 억 불의 기금을 조성한다는 것을 포함한다.

또한 개발도상국의 적응행동 이행을 지원하기 위하여, 선진국은 충분하고 예측가능하며 지속가능 한 재정, 기술 및 역량배양을 지원한다는 내용에 합의하였다.

\section{2. 평가}

동 합의문은 비록 법적인 구속력을 얻는 데에는 실패했지만, 협약의 기본원칙인 “공통의 그러나 차 
별화된 책임 (Common but Differentiated Responsibilities)”을 따르기 위한 노력을 기울였다고 평가할 수 있다. 예컨대 이러한 노력은 온실가스 감축을 위한 선진국 그룹과 개도국 그룹의 twotrack을 계속 유지하며, 온실가스 배출량의 정점 도달 시기가 개도국의 경우에 더 늦을 수 있음을 인식하는 부분에서 찾을 수 있다. 아울러 개도국의 기후변화 적응을 위한 선진국의 재정지원 및 기 술이전을 강조한 점도 협약의 기본원칙에 의거한 결과라 할 수 있다. 또한 온실가스 감축 수준과 관 련하여, 지구 평균온도 상승폭을 산업혁명 이전과 비교하여 $2{ }^{\circ} \mathrm{C}$ 이내로 제한하자는 과학적 근거에 기반한 결정을 내린 최초의 결정이라는 평가를 받고 있다.

그러나 온실가스 총량 및 국가별 감축량에 관한 구체적 언급이 제외되어 있으며, 교토의정서를 대 체할 만한 법적 구속력이 있는 합의가 아니라는 한계점을 갖고 있다. 또한 개도국에 대한 지원 규 모가 제시되었음에도 불구하고 개도국과 선진국 간의 입장 차이가 커서, 지원규모를 둘러싼 논란이 뒤따를 전망이다. 